\title{
THE EFFECT OF VACUUM DESICCATION ON THE VIRUS OF RABIES, WITH REMARKS ON \\ A NEW METHOD. ${ }^{*} \dagger$

\author{
D. L. HARRIS AND L. F. SHACKELI.
}

(From the Pathological Laboratory of the City Hospital and the Physiological Laboratory of St. Louis University.)

Shackell ${ }^{\mathrm{x}}$ has described an improved method of vacuum desiccation, the essential feature of which is that the material is kept solidly frozen during the process of drying. Animal tissues when dried by this method are preserved intact, show no shrinkage, are porous, and resist chemical changes and deterioration. In brief, the technique is as follows:

The material to be dried is placed in the bottom of a Scheibler's vacuum desiccating jar, in the upper part of which is a separate dish containing sulphuric acid. The temperature is reduced by placing the jar, half submerged, in a salt and ice mixture, and after thorough solidification of the material has resulted, a rapid vacuum is produced by a Geryk pump to less than $2 \mathrm{~mm}$. of mercury. During the process of desiccation, the temperature in the lower half should be kept several degrees below $0^{\circ} \mathrm{C}$. Unless the sulphuric acid be repeatedly shaken to prevent surface saturation with water, the time required for complete desiccation will be unduly prolonged.

Pasteur attenuated the virulence of rabic material by drying this in the presence of air over caustic potash. The time required for complete loss of virulence by this method depends upon the surrounding temperature. At $23^{\circ} \mathrm{C}$. this point is reached in from six to eight days. Vansteenberghe ${ }^{2}$ found that virulence may be maintained for several months if the brain be ground into a pulp, spread out in a very thin layer, and desiccated in vacuovery rapidly. $\mathrm{Marie}^{3}$ repeated this experiment with partial success.

\footnotetext{
- Received for publication October 25, rgro.

+ Read before the Laboratory Scction of the Amer ican Public Health Association, September 6, 19 ro

'Shackell, Am. Jour. Physiol., 1909, 24, p. 325.

- Vansteenberghe, Compi. rend. Soc. Biol., 1903, 55, p. 1646.

s Marie, L'etude experimentale de la rage.
} 
We have found that, by using Shackell's method of desiccation, brains and cords may be desiccated in toto without destruction of virulence. The time required for the complete extraction of water is about 24 to 36 hours. A number of brains have been so treated and the infectivity of all has been preserved. After the completion of desiccation, these brains were placed in an ordinary desiccating jar over sulphuric acid and left continually exposed to light at the ordinary room temperature. One brain has remained infective for four months. The only precaution taken was to guard against moisture. Material thus dried is like chalk and is easily pulverized. It is, however, very hygroscopic and, after a few hours' exposure to the air, becomes leathery and rapidly loses its infectivity. Experiments are now being carried on to compare quantitatively the virulence of desiccated cord with that of fresh cords, after the method described by Harvey and McKendick.

Harvey and McKendick ${ }^{x}$ have constructed a curve of infectivity which corresponds very closely to a curve representing the loss of weight of a cord when dried by the method of Pasteur. These writers state: "We may conclude that the small amount of water remaining in the cord from the ninth day onward is insufficient to keep the virus infective." It is the general belief that the attenuation of a rabic cord depends primarily upon its loss of water. Our work leads us to believe that it is the method of extracting the water which results in attenuation or destruction of virulence, and not the extraction of the water per se. To state it differently, slow desiccation attenuates and destroys the virus directly by reason of the concentration of salts and other substances which are in solution in the brain and cord. The action is therefore, in essence, a chemical one.

Desiccation of frozen material avoids any concentration of those intra- and extracellular salts or substances which are at the ordinary temperature in solution. With this method absolute dryness proceeds, cell by cell, from the surface. If this proposition be true, Vansteenberghe's and Marie's successes and failures are easy of explanation. These authors emphasize the fact that the cord must be spread in a very thin layer and the vacuum produced

× Harvey and McKendick, The Theory and Practice of Anli-rabic Immunization (Calcutta). 
very rapidly. A vacuum rapidly produced will freeze a small quantity of water in a bell jar. The success of these workers, in our opinion, depended upon the freezing of their thinly spread material and its drying without concentration. Further support is given to our hypothesis by the fact that exposure of our thoroughly dried material to ordinary air destroys its virulence completely within a few hours. The absorbed atmospheric moisture is, in this case, sufficient to redissolve some of the salts and other soluble material in a most concentrated state and destroy by chemical means the inclosed virus. 